\title{
The Effectiveness of Using Breastfeeding Program for Father via Facebook to knowledge, Attitude, Behavior of Supporting of 6-Month Exclusive Breastfeeding in Low-Income Country
}

Thiwawan thepha ( $\square$ tthiwawan@gmail.com )

Khon Kaen University https://orcid.org/0000-0002-5961-730X

Ampornpan Theeranut

Khon Kaen University Faculty of Nursing

Research

Keywords: six-month exclusive breastfeeding, social media, Facebook, Northeast Thailand, Quasiexperimental

Posted Date: September 23rd, 2021

DOI: https://doi.org/10.21203/rs.3.rs-915603/v1

License: (a) (i) This work is licensed under a Creative Commons Attribution 4.0 International License.

Read Full License 


\section{Abstract}

Background: The six-month exclusive breastfeeding rate in the Northeast region of Thailand has recently significantly decreased in contrast to all other regions in Thailand. Facebook is world widely use to increase that knowledge, attitude and behaviour to support breastfeeding. Therefore, the aim of this study is to test the effectiveness of using 6-month breastfeeding program for father via Facebook to knowledge, attitude, behavior of supporting of breastfeeding in low-income country.

Method: A quasi-experimental design was used. The study was carried out from September 2020 August 2021. The data of experimental group and control group were conducted in two tertiary hospital in Khonkaen province, Northeast Thailand. The participants were husbands of postpartum mothers who were admitted to the Obstetrics ward, Khonkaen Hospital, 2A and 2B ward, Srinagarin Hospital. The demographic data were analyzed by distribution of frequency, mean, percentage and standard deviation. The t-test were used to analyse the mean score of knowledge, attitude and behaviour of father by SPSS version 27.

Results: 72 father were included. The different mean score of knowledge, attitude, behaviors of father to support the EBF among baseline and 6-month were shown. In intervention group, the different mean score of knowledge among baseline and 6-month was significant at P-value 0.01 . The mean of knowledge at 6 months (mean=19.78, SD=5.50) was higher than the mean of knowledge baseline (mean=16.42, $S D=4.22$ ). Similarly, the different mean score of attitudes among baseline and 6-month was significant at P-value 0.14. The mean of attitude at 6-month (mean=108.03, SD=19.89) was higher than the mean of behaviour at baseline (mean=101.81, SD=17.99). In addition, the different score of behaviour among baseline (mean=65.86, SD=7.01) and 6-month (mean=68.58, SD=10.42) was significant at P-value=0.16. The mean score of behavior at baseline is lower than the mean of behaviour at 6 months. In control group, these is only the different mean of behavior baseline and 6-month was significant at P-value=0.00.

Conclusions: This confirm that FB is good platform to transfer the breastfeeding knowledge to father in low income country. In the future, this program can be improved and test in other country that has the same condition.

\section{Background}

In 2025, World Health Organization sets up the six-month exclusive breastfeeding (6-month EBF) as $50 \%$ of children in the world [1]. In Thailand, the 12th National Economic and Social Development Plan of Thailand 2017-2021 has set up the six-month EBF goal as same as WHO [2]. The statistic of six-month EBF in Thailand had been increased form $12.3 \%$ in 2013 to $23 \%$ in 2016 [2]. However, this target is far from the 6-month EBF target of Thailand and WHO. Therefore, to reach the goal of 6-month EBF rate is important.

In both internationally and in Thailand, many factors influence to six-month EBF. Mother factors are age, educational level, occupation, economic status, health status, EBF knowledge, breastfeeding confidence, 
breastfeeding believe, the duration of maternity leave [3-8]. Infant factors are infant health, infant temperament, lack of effective suckling $[3,8]$. Healthcare, such as the healthcare service, healthcare access, EBF knowledge, EBF attitude, and EBF skill of healthcare professional, EBF policy, is another factor $[4,9,10]$. The last factor is social such as workplace and family [4]. The study show that the father's knowledge, attitude and behavior to support the 6-month exclusive breastfeeding affect to the duration of 6-month $\operatorname{EBF}[3,7]$. In addition, social media has been reported as the new factors to increase the duration of six-month EBF in low-income country [4].

Social media is a method to communicate, transfer, distribute information, exchange knowledge, news among people [11]. Social media is now widely used in business, government, and public health through various applications such as Facebook, web pages, LINE applications, etc[11]. The statistic in Thailand which is low income country show that, in 2015 , up to $56 \%$ of Thai people can access and use social media [12]. Social media has a positive effect on healthy behavior modification [13]. In addition, social media is a tool in order to service postpartum mothers. It also helps as a communication tool among health teams [11]. In northeast Thailand, social media as Facebook is factor affecting exclusive breastfeeding for 6 months as a way to find knowledge about breastfeeding exclusively for 6 months, to express feelings, to solve problems related to breastfeeding. It is also an encouragement among mothers who are breastfeeding as well[4]. Therefore, social media especially FB has been recommended as an instrument to increase the EBF knowledge, change behavior of family member, nanny, and healthcare team to support EBF for 6 months [5].

Facebook (FB) is one of social media platform. Currently, there are more than 4 billion Facebook users worldwide. In 2018, Thailand had 45 million Facebook users, 23 million males and 22 million females [14], aged 18-24 years. The highest total usage was 16.0 million accounts, followed by users aged 2534 [14]. Facebook is used for a variety of purposes, such as education, advertising, education health care, etc. $[15,16]$, including promoting breastfeeding $[17,18]$. Using Facebook can be a source of knowledge and help promote group support allows mothers to breastfeed longer[18]. However, Facebook has not been used to encourage and promote breastfeeding among husbands. One important factor affecting the duration of breastfeeding is the husband. The husband is the one who is close to the mother after giving birth. He is a person who has contributed to the encouragement, support for postpartum mothers. Husbands are therefore a group of people who healthcare professional should pay attention to in promoting breastfeeding. A review of the literature on the promotion of breastfeeding found that the duration of breastfeeding was correlated with the support of the husbands. The husband has both a physical and psychological influence on the postpartum mother[4, 19] In Thailand, most husbands work outside the home. This can lead the lack of opportunity to participate in the promotion of breastfeeding of husband. Therefore, healthcare professional should pay attention by increasing knowledge, creating positive attitudes and encourage behaviors that promote breastfeeding for husbands who work outside the home. In addition, the amount of using social media especially FB, to educate and promote positive behavior to 6-month EBF increase. Therefore, the breastfeeding program for father via Facebook has been developed. 
The aim of this study is to test the effectiveness of using 6-month breastfeeding program for father via Facebook to knowledge, attitude, behavior of supporting of breastfeeding in low-income country.

\section{Methods}

\section{Design and participants}

A quasi-experimental design was used to evaluate outcomes of the 6-month breastfeeding program for father via facebook on knowledge, attitude and father's behaviour to support the 6-month breastfeeding in low-income country. The study was carried out from September 2020 - August 2021. The data of experimental group and control group were conducted in two tertiary hospital in Khonkaen province, Northeast Thailand. The participants were husbands of postpartum mothers who were admitted to the Obstetrics ward, Khonkaen Hospital, 2A and 2B ward, Srinagarin Hospital. The inclusion criteria were a husband who works from home/outside for 6-8 hours a day, age 20-60 years, being the husband of the mother after giving birth (Normal delivery/caesarean) 1-4 days, Being the father of an infant born 1-4 days with normal conditions and no restrictions on breastfeeding, able to communicate and able to read and write Thai language, willingness and consent to cooperate in research, able to bring the child to have a health check and vaccination at the good boy clinic at the hospital for 1, 2, 4 and 6 months. The withdrawal criteria were during the activity, participants participate in the program or do not voluntarily participate in the program or their infant is prohibited from breastfeeding or unable to breastfeed. The purposive sampling were using to include the participants and the participants were randomly assigned to a control group and an experimental group by means of random sampling.

The experimental group joined the 6-month breastfeeding program for father via Facebook. This intervention was designed based on knowledge transformation concept which included the explicit knowledge and tacit knowledge. This intervention consists of 3 parts: 1) A 6-month EBF education package; this package was set on Facebook platform in the form of Info graphic. The content included the benefits of breastfeeding, factors affecting the amount of breastmilk, how to breastfeed, hold, express milk, common problems in breastfeeding. Participants were received this knowledge package for the first 1-3 days after the baby is born. The participants can self-learn repeatedly. 2) Facebook page: Researchers presented 6-moth EBF information at least one time per week to encourage positive attitudes about 6-month EBF. 3) Group Counseling Forum; The participants can use this channel to share experience and get advice on breastfeeding problems with other participants. The control group was join the standard care.

There are four instruments. 1) The demographic questionnaire includes age, income, education level, the number of children. 2) The father EBF knowledge questionnaire includes 11 questions. The total score was from 0-40.3) The father attitudes questionnaire includes 19 questions. There are both positive and negative question with five scales (Likert scale); Strongly disagree (1 point), Disagree (2 points), Not sure (3 points), Agree (4 points), Strongly agree (5 points). The total score was from 19-95. 4) The father's behavior questionnaire includes 30 questions. There are both positive and negative question with five 
scales (Likert scale); Never (1 point), Rarely (2 points), Occasionally (3 points), Often (4 points), Very often (5 points). The total score was from is 30-69 points. The data were collected twice time both experimental group and control group. First time is baseline and second time was 6-month after delivery children.

The demographic data were analyzed by distribution of frequency, mean, percentage and standard deviation. The t-test were used to analyse the mean score of knowledge, attitude and behaviour of father by SPSS version 27. The Ethical approval was granted by the College Ethics Review Board (CERB), Khonkaen university (HE631345) as well as the Khonkaen Hospital Ethics Committee, Thailand (KEMOU63021).

\section{Results}

72 father include 36 father in experimental group and 36 father in control group. No participants withdrew from the study. Most of the participants in both intervention group and control group were aged between 30-39 years. Similarly, the education level of these both groups are the same. Most of participants graduated from bachelor's degree. Most of the sample had income in the range 10,001-20,000 baht per month. More than half of the participants had children and experienced breastfeeding.

The different mean score of knowledge, attitude, behaviors of father to support the EBF among baseline and 6-month were shown. In intervention group, the different mean score of knowledge among baseline and 6-month was significant at P-value 0.01 (Table 2). The mean of knowledge at at 6 months (mean = $19.78, S D=5.50$ ) was higher than the mean of knowledge baseline (mean $=16.42, S D=4.22)$. Similarly, the different mean score of attitudes among baseline and 6-month was significant at P-value 0.14 (Table 2). The mean of attitude at 6-month (mean $=108.03, S D=19.89$ ) was higher than the mean of behaviour at baseline (mean $=101.81, S D=17.99)$. In addition, the different score of behaviour among baseline (mean $=65.86, \mathrm{SD}=7.01)$ and 6-month (mean $=68.58, \mathrm{SD}=10.42)$ was significant at $\mathrm{P}$-value $=$ 0.16 (Table 2). The mean score of behavior at baseline is lower than the mean of behaviour at 6 month. In control group, these is only the different mean of behavior baseline and 6-month was significant at Pvalue $=0.00$ (Table 2 ) . 
Table 1

The characteristic of participants.

\begin{tabular}{|c|c|c|}
\hline Items & $\begin{array}{l}\text { The intervention group } \\
\mathbf{N}(\%)\end{array}$ & $\begin{array}{l}\text { The control group } \\
\mathrm{N}(\%)\end{array}$ \\
\hline \multicolumn{3}{|l|}{ Age (year) } \\
\hline $19-29$ & $10(27.78)$ & $8(22.22)$ \\
\hline $30-39$ & $13(36.11)$ & $22(61.11)$ \\
\hline $40-49$ & $12(33.33)$ & $3(8.33)$ \\
\hline $50-59$ & $1(2.78)$ & $3(8.33)$ \\
\hline \multicolumn{3}{|l|}{ Education level } \\
\hline High school & $15(41.67)$ & $16(44.44)$ \\
\hline Bachelor degree & $20(55.56)$ & $18(50.00)$ \\
\hline Over Bachelor degree & $1(2.78)$ & $2(5.56)$ \\
\hline \multicolumn{3}{|l|}{ Incomes (Baht/month) } \\
\hline $1-10,000$ & $0(0)$ & $2(5.56)$ \\
\hline $10,001-20,000$ & $22(61.11)$ & $20(55.56)$ \\
\hline $20,001-30,000$ & $10(27.78)$ & $9(25.00)$ \\
\hline $30,001-40,000$ & $4(11.11)$ & $5(13.89)$ \\
\hline$>40,000$ & $0(0)$ & $1(2.78)$ \\
\hline \multicolumn{3}{|c|}{ History of having children } \\
\hline No & $12(33.33)$ & $15(41.67)$ \\
\hline Yes & $24(66.67)$ & $21(58.33)$ \\
\hline \multicolumn{3}{|c|}{ Breastfeeding experience } \\
\hline No & $12(33.33)$ & $11(30.56)$ \\
\hline Yes & $24(66.67)$ & $25(69.44)$ \\
\hline \multicolumn{3}{|c|}{ Taking a leave with wife } \\
\hline No & $20(55.56)$ & $26(72.22)$ \\
\hline Yes & $16(44.44)$ & $10(27.78)$ \\
\hline
\end{tabular}


Table 2

The knowledge, attitude, behaviour of father to supporting breastfeeding between baseline and 6-month Items

Baseline

Mean SD 6-month

Mean SD
The mean difference
The SD difference $\mathbf{t}$

$P$

\section{Knowledge}

Intervention

group

$16.42 \quad 4.22$

19.78

$5.50 \quad 3.36$

7.74

$2.60 .01^{*}$

Control group $\quad 19.39$

4.15

19.53

4.55

0.14

5.50

$0.15 \quad 0.88$

Attitude

Intervention

group

101.81

$\begin{array}{lll}17.99 & 108.03 & 19.89\end{array}$

6.22

24.49

1.53

$0.14^{*}$

Control group

105.11

14.57

106.69

$20.83 \quad-1.58$

23.35

$-0.40$

0.68

\section{Behaviour}

Intervention

group

$65.86 \quad 7.01$

$68.58 \quad 10.42$

2.72

11.37

1.44

$0.16^{\star}$

Control group

63.75

8.74

69.17

$\begin{array}{ll}7.19 & 5.42\end{array}$

10.98

2.96

0.00 *

Table 3

The knowledge, attitude, behaviour of father to supporting breastfeeding between experimental group and control group

\begin{tabular}{|c|c|c|c|c|c|c|c|c|}
\hline \multirow[t]{2}{*}{ Items } & \multicolumn{2}{|c|}{$\begin{array}{l}\text { Intervention } \\
\text { group }\end{array}$} & \multicolumn{2}{|c|}{ Control group } & \multirow[t]{2}{*}{$\begin{array}{l}\text { The mean } \\
\text { difference }\end{array}$} & \multirow[t]{2}{*}{$\begin{array}{l}\text { The SD } \\
\text { difference }\end{array}$} & \multirow[t]{2}{*}{$\mathbf{t}$} & \multirow[t]{2}{*}{$P$} \\
\hline & Mean & SD & Mean & SD & & & & \\
\hline \multicolumn{9}{|c|}{ Knowledge } \\
\hline Baseline & 16.42 & 4.22 & 19.39 & 4.15 & 0.25 & 6.79 & -2.62 & 0.01 * \\
\hline 6 month & 19.78 & 5.50 & 19.53 & 4.55 & -2.97 & 6.89 & 0.22 & 0.82 \\
\hline \multicolumn{9}{|l|}{ Attitude } \\
\hline Baseline & 101.81 & 17.99 & 105.11 & 14.57 & 2.92 & 2.74 & 0.84 & $0.40^{*}$ \\
\hline 6 month & 108.03 & 19.89 & 106.69 & 20.83 & -4.89 & 27.30 & -1.07 & $0.29 *$ \\
\hline \multicolumn{9}{|c|}{ Behaviour } \\
\hline Baseline & 65.86 & 7.02 & 63.75 & 8.74 & -0.58 & 10.79 & 1.17 & $0.24^{*}$ \\
\hline 6 month & 68.58 & 10.42 & 69.17 & 7.19 & 2.11 & 11.88 & -0.30 & 0.77 \\
\hline
\end{tabular}


The different mean score of knowledge, attitude, behaviors of father to support the EBF among intervention group and control group were shown. In baseline, the mean score of knowledge, attitude and behaviour among intervention group and control group were significant at $P$-value $=0.01,0.04,0.24$, respectively. At 6 month, only the different mean of attitude among intervention group (mean $=108.03, S D$ $=19.89)$ and control group (mean $=106.69, S D=20.83)$ was significant at $P$-value $=0.29$.

\section{Discussion}

The results of the study show that the breastfeeding knowledge, attitude, and behavior of the father to support breastfeeding can improve by this intervention. This is a good evidence showing that fathers can learn more knowledge about breastfeeding when the father participate in breastfeeding education. This result is similar with the study in China. It shows that father who attended that BF education program had the high score of BE knowledge than the father who are not attended the program[20]. In addition, the FB program can increase the breastfeeding knowledge of father in low-income country. In Africa, the breastfeeding FB program was effective to rise the knowledge of participants and also increase the intention and the duration of breastfeeding[17]. In term of breastfeeding attitude, the breastfeeding attitude of father who joined this FB program was reported as the high score than the attitude in control group. Similarly, the breastfeeding attitude of mother who are attended FB program had been increased after attended FB and was higher than mother who did not attended. In term of behavior, the results show that the mean score of behavior of father to support breastfeeding who attend this FB program was high than the mean score of behavior of father to support breastfeeding who did not attend this FB program. It is similar with the study in Vietnam. The study shows that father who join that education program had the mean score of behavior to support breastfeeding support is higher than father who did not attend the education program. This can be concluded that Breastfeeding program for father via Facebook affected to the knowledge, attitude, behaviour of supporting of breastfeeding of father. This program should be continued using for father in northeast Thailand.

The main strength of the current study was that it included fathers who are various ages, educational level, backgrounds, income, and breastfeeding experience. Using a quantitative approach allowed for a generalization. A limitation of this study is that father who do not interesting in breastfeed were not included, but this was not the focus of this study.

\section{Conclusions}

This study is to test the effectiveness of using breastfeeding program for father via Facebook to knowledge, attitude, behavior of supporting of breastfeeding in low-income country. The result shows that the mean score of knowledge, attitude, and behaviour to support breastfeeding of father increased after attend the breastfeeding program for father via Facebook. This confirm that FB is good platform to transfer the breastfeeding knowledge to father in low income country. In the future, this program can be improved and test in other country that has the same condition. 


\section{Abbreviations}

AM

Ampornpan Theeranut

EBF

Exclusive breastfeeding

FB

Facebook

TT

Thiwawan Thepha

SM

Somjit Muangpin

\section{Declarations}

There are not declarations.

\section{Ethics approval and consent to participate}

- Ethical approval was granted by Center for Ethics in Human Research, Khonkaen University, Thailand (No. HE631345).

- Consent for publication

- We used one consent form to get consent for the individual data and to digitally record the data collection.

- Availability of data and material

- Not applicable.

- Competing interests

- The authors declare that they have no competing interests.

- Funding

- This research project was financial supported by the young researcher development project of Khon Kaen University, Thailand.

- Authors' contributions

- All authors made substantial contributions to the conception and design of the research.

TT collected and analyzed the data, and drafted the article. AT and SM provided revision of the article. All authors gave final approval for the article.

\section{Authors' information}

Thiwawan Thepha, RN, PhD, Midwife, Lecturer, Department of Midwifery, the Faculty of Nursing, Khonkaen University, Thailand. 
Address: Department of Midwifery, Faculty of Nursing, Khonkaen University, 123 Mittapap Road, Khonkaen, Thailand 40002 Tel: +66 43202407 Fax: + 6643348301

E-mail: tthiwawan@kku.ac.th

Ampornpan Theeranut, RN, PhD, Associated professor, Department of Adult, Faculty of Nursing, Khonkaen University, Thailand.

Address: Department of Adult, Faculty of Nursing, Khonkaen University, 123 Mittapap Road, Khonkaen, Thailand 40002

Tel: +66 43202407 Fax: + 6643348301

E-mail: sompha@kku.ac.th

Somjit Muangpin, RN, PhD, Midwife, Assistant professor, Department of Midwifery, Faculty of Nursing, Khonkaen University, Thailand.

Address: Department of Midwifery, Faculty of Nursing, Khonkaen University, 123 Mittapap Road, Khonkaen, Thailand 40002

Tel: +66 43202407 Fax: + 6643348301

E-mail: sompha@kku.ac.th

\section{- Acknowledgements}

We gratefully acknowledge all participants and also the head of 2B ward, Srinagarin hospital, and Postpartum ward, Khonkaen Hospital, Khonkaen, Thailand who enabled the data collection.

\section{References}

1. WHO. Exclusive breastfeeding [Internet]. 2017 [cited 2019 Nov 28]. Available from: http://www.who.int/maternal_child_adolescent/topics/newborn/nutrition/breastfeeding/en/.

2. Thailand NSO. Thailand multiple indicator cluster survey 2015-2016. Bangkok, editor. Statistical forecasting bureau;; 2016.

3. Thepha T, Marais D, Bell J, Muangpin S. Facilitators and Barriers to Exclusive Breastfeeding in Thailand: A Narrative Review. J Community Public Heal Nurs. 2017;03(01).

4. Thepha T, Marais D, Bell J, Muangpin S. Perceptions of northeast Thai breastfeeding mothers regarding facilitators and barriers to six-month exclusive breastfeeding: Focus group discussions. Int Breastfeed J. 2018;13(1).

5. Thepha T, Marais D, Bell J, Muangpin S. Concept mapping to reach consensus on a 6-month exclusive breastfeeding strategy model to improve the rate in Northeast Thailand. Matern Child Nutr. 
2019;15(4).

6. Hmone MP, Dibley MJ, Li M, Alam A. A formative study to inform mHealth based randomized controlled trial intervention to promote exclusive breastfeeding practices in Myanmar: Incorporating qualitative study findings. BMC Med Inform Decis Mak. 2016;16(1).

7. Nduna T, Marais D, van Wyk B. An Explorative Qualitative Study of Experiences and Challenges to Exclusive Breastfeeding Among Mothers in Rural Zimbabwe. Infant, Child. Adolesc Nutr. 2015;7(2):69-76.

8. Couto GR, Dias V, Oliveira I de. J. Benefits of exclusive breastfeeding: An integrative review. Nurs Pract Today. 2020;7(4):245-54.

9. UNICEF. Removing the barriers to breastfeeding: a call to action. [Internet]. 2018 [cited 2019 Nov 28]. Available from: https://www.unicef.org.uk/babyfriendly/removing-barriers-breastfeeding-uk/.

10. Radzyminski S, Callister LC. Health Professionals' Attitudes and Beliefs About Breastfeeding. J Perinat Educ. 2015;24(2):102-9.

11. Fuchs C. Social media a critical introduction. London: SAGE; 2017.

12. Veevdil. Digital, social, and mobile media statistic of Thailand in 2016 [Internet]. 2016 [cited 2017 Aug 9]. Available from: http://www.veedvil.com/news/digital-in-thailand-2016/.

13. Merolli M, Gray K, Martin-Sanchez F. Health outcomes and related effects of using social media in chronic disease management: A literature review and analysis of affordances. J Biomed Inform. 2013;46(6):957-69.

14. Wittawin A. Infographic: Facebook user in Thailand [Internet]. 2019. Available from: https://www.thumbsup.in.th/facebook-thailand-insight.

15. Andreou A, Silva M, Benevenuto F, Goga O, Loiseau P, Mislove A. Measuring the Facebook Advertising Ecosystem. 2019.

16. Wang J, Stamos A. Information Operations and Facebook. USA: Facebook Inc.; 2017.

17. Robinson A, Lauckner C, Davis M, Hall J, Anderson AK. Facebook support for breastfeeding mothers: A comparison to offline support and associations with breastfeeding outcomes. Digit Heal. 2019;5.

18. Bridges N, Howell G, Schmied V. Exploring breastfeeding support on social media. Int Breastfeed J. 2018;13(1).

19. Jama A, Gebreyesus $H$, Wubayehu T, Gebregyorgis $T$, Teweldemedhin $M$, Berhe $T$, et al. Exclusive breastfeeding for the first six months of life and its associated factors among children age 6-24 months in Burao district, Somaliland. Int Breastfeed J. 2020;15(1).

20. Su M, Oyoung O. Father's role in breastfeeding promotion: Lessons from a quasi-experimental trial in China. Breastfeed Med [Internet]. 2016;11(3):144-9. Available from:

http://www.embase.com/search/results?

subaction=viewrecord\&from=export\&id=L610073512\%0Ahttp://dx.doi.org/10.1089/bfm.2015.0144. 